\title{
Goal Setting with ICF (International Classification of Functioning, Disability and Health) and Multidisciplinary Team Approach in Stroke Rehabilitation
}

\author{
Matilde Leonardi and Klemens Fheodoroff
}

\section{Introduction}

Stroke is among the leading causes for adult disability. The impairments associated with a stroke display a wide variety of clinical signs and symptoms. Therefore, an interdisciplinary team approach with different experts working cohesively and closely together has been identified as fundamental for effective stroke rehabilitation programs (Teasell et al. 2016a). There is high-confidence evidence on the benefits of the stroke care units and moderate-confidence evidence that integrated, multidisciplinary care teams improve stroke outcome. Within this team approach, coordination and cooperation appear to be key factors for reaching best results within the limitations imposed by stroke-related impairments as well as by contextual factors such as limited time for in-patient rehabilitation or limited resources in community-based rehabilitation programs (see chap.14).

The long-term and transversal nature of care and treatment for stroke have all served to confound hospital traditional, fragmented and top-down led responses. Meanwhile, it became apparent that stroke patients, like all patients with chronic health conditions, are in special need of continuous care, requiring a longitudinal, integrated and multidisciplinary network approach linking health and social care (paradigm shift). Policies, system and services, including payment systems, should be able to cope with care provided in more than one setting. To address the issue of fragmentation and overcome treatment gaps from a health services delivery perspective, it is necessary to 'optimize care and rationalize costs'. There is a need for a healthcare system transformation based on shared-vision and a practical roadmap

\author{
M. Leonardi $(\square)$ \\ Fondazione IRCCS Istituto Neurologico Carlo Besta, Milan, Italy \\ e-mail: Matilde.Leonardi@istituto-besta.it \\ K. Fheodoroff \\ Gailtal-Klinik, Hermagor, Austria
}

(C) The Author(s) 2021

T. Platz (ed.), Clinical Pathways in Stroke Rehabilitation, https://doi.org/10.1007/978-3-030-58505-1_3 
to implementation of a coordinated system at national and regional level (WHO and UNESCO 2010).

In such a system early diagnosis, treatment and rehabilitation are seen as one seamless process of actions across different healthcare professionals and complementary disciplines (e.g. hospitals, specialists care, primary care, community care, homecare, institutional care or nursing home, pharmacies) that should work together according to a team-based approach in order to deliver patient care and improve health outcomes.

To ensure the continuity of care from the very beginning after a stroke, early intervention is key for optimal management of the disease and for achieving better clinical outcomes. A large body of research links early intervention to measurable health gains such as improved survival rates, reduced disability and complication rates, better quality of life and lower treatment costs (Stroke Unit Trialists 2013).

Optimizing healthcare processes with an outcome-based approach achieving high value for patients is the overarching goal of healthcare delivery, with value defined as the health outcomes achieved per money spent. Treatment is based on the needs of the patient ('demand') instead of on the offer/supply of treatment structures. Each age group according to disease stage has specific needs to be addressed along the care process (biological, psychological, healthcare services, social needs). Care for persons with stroke usually involves multiple specialties and numerous interventions, with final outcomes determined by interventions across the full cycle of care. Measuring, reporting and comparing outcomes are essential to improve outcomes and make informed choices about how to optimize healthcare and rationalize costs (Teasell and Hussein 2016).

Goal setting has been recognized as a core process in managing complex situations, which are challenging service providers in daily routine. Nevertheless, agreed standards on goal setting and evaluation still need to be defined. Many factors such as types and number of goals, the impact of patient involvement in the goal setting and evaluation process or the influence of goal attainment on adherence, selfefficacy and health-related quality of life (HR-QoL) have not been evaluated in the context of stroke rehabilitation in a rigorous way including randomized controlled trials (RCTs). (Rosewilliam et al. 2011; Sugavanam et al. 2013). Currently only low-to-moderate evidence on effectiveness of goal setting and evaluation practice on psychosocial factors (HR-QoL, emotional status and self-efficacy) is available (Levack et al. 2015).

For years, neurorehabilitation has been searching for an agreed framework suitable for interdisciplinary documentation. The International Classification of Functioning, Disability and Health (ICF), (WHO 2001) based on a biopsychosocial model of health and disability, offers such a framework. ICF is helpful in establishing a common language between different professionals and different stakeholders such as stroke patients, caregivers, administrative and health policy providers. It might also serve as the basis for a shared documentation system. Disability in ICF is defined as the interaction of health condition with hindering or facilitating environmental factors. 
In this chapter, we highlight some aspects with relevance for multidisciplinary team building and coordination and for using the ICF in the context of stroke rehabilitation; in detail, how to describe individual levels of functioning and to set treatment goals as well as to identify barriers and facilitators to functioning and health.

\section{Methodological Considerations}

This chapter fulfils an educational purpose by introducing concepts and their application in stroke rehabilitation related to the ICF (WHO 2001) as a common language to describe individual functioning in a given context, multidisciplinary team building and coordination as well as goal setting. As such, it is primarily heuristic and not evidence-driven.

Hence, a systematic search for evidence is not the basis for this chapter. The most up-to-date relevant evidence is nevertheless reported.

The recommendations given in this chapter follow the same rules as outlined in chapter "Clinical Pathways in Stroke Rehabilitation: Background, Scope, and Methods" (see chap. 2): The level of evidence that served as basis for a recommendation is provided according to the 'Oxford Center for Evidence-Based Medicine - Levels of Evidence' (CEBM 2009) ranging from 'expert opinion' ('5') to 'systematic review (with homogeneity) of RCTs' ('1a'). The quality of the evidence is rated with the GRADE approach (Grading of Recommendations, Assessment, Development and Evaluation) (Schünemann et al. 2013) reflecting our confidence in an estimate of therapeutic effect that can range from very low to high. In addition, GRADE specifies two categories of strength of recommendation, i.e. a weak ('B', 'should') or a strong ('A', 'ought to') recommendation in favour ('+') or against ('-') an intervention, mainly for high- or moderate-quality evidence (Schünemann et al. 2013). A third category of recommendation was introduced indicating a therapeutic 'option' ('0', 'can'), mainly based on low- or very low-quality evidence (Platz 2017). Deviations are indicated by their reason, e.g. when upgrading a recommendation that is supported by low quality of evidence only to a 'week recommendation' instead of formulating an 'option': 'B+ [clinical reasoning]'.

\section{$3 \quad$ Multidisciplinary Team Building and Coordination}

Organized stroke care has been identified as an important factor for better overall outcomes for individuals with stroke (Teasell et al. 2016b).

\subsection{Improving Quality of Stroke Care}

Stroke is a leading cause of disability and death among adults. It is the second cause of death worldwide and the first cause of acquired disability. Despite improvements 
in care, around one-third of the 1.3 million people who have a stroke in Europe each year will not survive. One-third will make a good recovery, but one-third will live with long-term disability. Furthermore, stroke might lead to post-stroke dementia, depression, epilepsy and falls that cause substantial morbidity and economical costs. Strokes are more likely to occur with ageing with $75 \%$ of strokes happening to people older than 65 years. However, $25 \%$ of strokes still occur in younger people of working age, resulting in a significant loss of productivity.

Care for stroke patients starts before a stroke has happened (primary prevention) with the identification of people at risk for stroke, modification of lifestyle patterns and treatment of vascular risk factors in the primary care setting. It then focuses on optimal treatment of acute stroke in stroke units and on avoiding further vascular events (secondary prevention), ideally delivered through a comprehensive stroke service (Stroke units Trialists 2013). The effect of acute treatment is dependent on the time from stroke onset. Every step of the patient trajectory from symptom onset to the start of treatment within the hospital should be optimized in order to save time and to offer all opportunities for minimizing brain tissue damage. A shorter delay from onset of symptoms to treatment with intravenous thrombolysis (IVT) and thrombectomy can make the difference between being independent or dependent on help from others. During and after the acute phase, targeted rehabilitation is needed to reduce the remaining deficits to a minimum, to optimize the level of individual functioning and to reintegrate stroke victims into normal life.

\subsection{Low Access to Rehabilitation}

Many stroke survivors experience impairments making them dependent on others for their daily tasks. As stated in article 26 of the UN Convention on the Rights of Persons with Disability, rehabilitation aims to 'enable persons with disabilities to attain and maintain maximum independence, full physical, mental, social and vocational ability, and full inclusion and participation in all aspects of life. To that end, States Parties shall organize, strengthen and extend comprehensive habilitation and rehabilitation services and programmes, particularly in the areas of health, employment, education and social services...' (UN 2007). The early rehabilitation process after stroke is best initiated in a stroke units. However, it is rarely complete when it is time to leave hospital, impacting on goal pursuit and goal adaption (Brands et al. 2014). Although it has been shown that continued rehabilitation after discharge during the first year after stroke reduces the risk of disability, only very few clinical trials have been conducted in this field. Therefore, many of the recommendations for treatment in this field are weak, and investment in research in this area is essential.

Improving the access to timely and effective rehabilitation is a crucial point for stroke patients. Access to timely and individualized rehabilitation should be available to all stroke patients, through development of stroke units linked with rehabilitation services matched to patient needs, from community-based early supported discharge up to comprehensive inpatient rehabilitation units. 
To address the complex disabilities arising from stroke, an interdisciplinary group of professionals with complementary skills is essential. Team composition and size may vary in different settings. Core disciplines in most stroke rehabilitation units include neurology and rehabilitation medicine, nursing, occupational therapy (OT), physiotherapy (PT), speech and language therapy (SLT) and case management/social work. (Teasell et al. 2016b). While frequently not available, a neuropsychologist would be important to integrate in teams given the high prevalence of cognitive and emotional disorders post-stroke and their relevance for disability (Ayerbe et al. 2013; Wagle et al. 2011).

Strasser (Strasser et al. 2005, 2008) demonstrated relations between team processes-how a team deals with coordinating and communicating its work, and the attitudes and perceptions expressed by its members-and patient outcomes. If patients were treated by more structured teams that made greater use of patient outcome data, patients experienced greater functional gains. Regular meetings to discuss patients' progress and plan treatment are the main process by which multidisciplinary teams operate and coordinate. Tyson developed-and subsequently tested-a framework of features for successful team meetings, including premeeting preparation of participants, setting an agenda, skilled chairing, using a structured documentation and the formal use of standardized measurement tools. Following implementation, all aspects of meeting quality improved by $5 \%-58 \%$ without loss of staff productivity or additional resources. In a longitudinal follow-up design, they found a greater increase in Barthel Index score after implementation, indicating greater functional recovery (Tyson et al. 2014a, 2015) (Fig. 1).

\begin{tabular}{|c|c|c|}
\hline \multicolumn{3}{|c|}{ 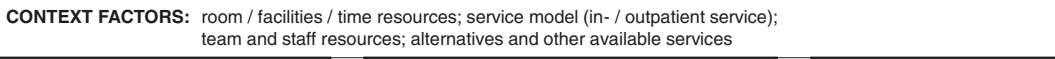 } \\
\hline MEETING INPUTS & MEDIATING PROCESSES & MEETING OUTPUTS \\
\hline $\begin{array}{l}\text { PERSONAL CONTRIBUTION } \\
\text { - Personal presence } \\
\text { - Preparation: } \\
\text { knowledge about patient history } \\
\text { current capacity / performance } \\
\text { barriers / facilitators } \\
\text { - Active and goal-oriented contribution }\end{array}$ & $\begin{array}{l}\text { LEADERSHIP } \\
\text { - Chairing skills: Time keeping; } \\
\text { - Nature of the talk; accuracy } \\
\text { - Leadership style } \\
\text { - Power relationships }\end{array}$ & $\begin{array}{l}\text { - Information exchanged } \\
\text { - Progress monitored } \\
\text { - Decisions made } \\
\text { - Action plans agreed } \\
\text { - Goals reviewed } \\
\text { - Actions allocated }\end{array}$ \\
\hline MEETING STRUCTURE & TEAM / SOCIAL CLIMATE & $\begin{array}{l}\text { FEATURES OF } \\
\text { SUCCESSFUL MEETINGS }\end{array}$ \\
\hline $\begin{array}{l}\text { - Specific meeting agenda } \\
\text { - Specific documentation } \\
\text { - Use of standardised assessment } \\
\text { tools } \\
\text { - Goal setting and action planning }\end{array}$ & $\begin{array}{l}\text { - Professional vs patient focus } \\
\text { - Professional vs team role } \\
\text { - Atmosphere } \\
\text { - Team interaction and interpersonal } \\
\text { relationships }\end{array}$ & $\begin{array}{l}\text { - Comprehensive / holistic } \\
\text { - Objective, relevant } \\
\text { - Patient focussed, respectful } \\
\text { - Timely, accurate } \\
\text { - Concise, Consistent }\end{array}$ \\
\hline
\end{tabular}

Fig. 1 Conceptual framework for multidisciplinary team meetings in stroke rehabilitation. (Modified from Tyson et al. 2014a) 


\subsection{The Chronic Care Model for Stroke Patients}

From an international perspective, the paradigm shift is leading to the transformation of health care and illustrates one or perhaps the most applied strategy for improving the quality of care for people with chronic conditions such as many brain disorders which is the Multimorbidity Chronic Care Model (Palmer et al. 2018). This care model is of particular interest for the management of stroke and its high complexity. This complexity must be better understood if people's needs are to be properly addressed. The EU joint action JA-CHRODIS (2013-16) identified best practices and effective interventions for management of chronic diseases and developed this Multimorbidity Chronic Care Model (MCCM). To develop it, first, the five components from the Chronic Care Model (Wagner 1998) and the Innovative Care for Chronic Conditions Model (Epping-Jordan et al. 2004) were identified: self-management support; delivery system design; decision support; clinical information systems and interaction with community partners. The aim of MCCM is to meet patient's needs and transform daily care for patients with chronic diseases from a system that is essentially reactive - responding mainly when a person is sick-to one that is proactive and focused on patient-oriented care. It is designed to accomplish these goals through a combination of effective team care and planned interactions with the patients; self-management support; patient registries and other supportive information technology such as digital solutions allowing better exchange of information.

These elements are designed to work together to strengthen the healthcare providers-patient relationship and improve health outcomes. MCCM could be the model for better stroke patients' management and care and summarizes the basic elements for improving care in health systems at the community, organization, practice and patient levels.

Another important concept for the organization of care is emerging with the principle of 'patient-centred care': a person living with stroke has needs that evolve according to the stage of his/her disease (Brands et al. 2012, 2014):

- biological needs (mainly the relief of the physical symptoms, as pain),

- psychological needs (need for tailored information, e.g. on treatment options, evolution of the disease; and need for psychological support to deal with emotions such as fear, frustration, depression and distress),

- need and implementation of care plans may be an additional support to coordinate medical care, paramedical care and well-being,

- ongoing support in areas such as housing, employment, social relationships and community participation.

The reorganization of care delivery requires a paradigm shift and the adoption of three intertwined principles, namely: patient-centred care, improved hospital efficiency and interventions in an optimal setting, either in hospitals, at home or in communities. All these developments underpin the need to address the integration between the different healthcare providers and the different settings.

Efforts to empower stroke patients to be engaged in responding to their health needs may improve health outcomes, adherence to treatment and has the potential for patients to make more informed decisions with regard to their health. 
By overcoming fragmentation and by creating linkages between services along the full continuum of care improved quality, continuity and efficiency in the delivery of services may be realized and ultimately improved health outcomes secured.

In stroke rehabilitation, a holistic view on functioning and disability of the individual beyond impairments is necessary to establish an individualized and comprehensive treatment program. Information on personal factors such as education, work and employment, recreation and leisure as well as information on environment such as housing, support and relationship should be available to all members of the interdisciplinary team responsible for the patient. Furthermore, a capacity check in different areas of interest, such as swallowing, mobility, selfcare and interpersonal interactions, is necessary for setting goals and planning appropriate interventions.

The World Health Organization's International Classification of Functioning, Disability and Health (ICF) (WHO 2001) based on an integrative model of health provides a holistic, multidimensional and interdisciplinary understanding of health and health-related conditions. According to the ICF, the problems associated with a disease may concern body functions and body structures and activities and participation in life situations. Health states and the development of disability are modified by contextual factors, including environmental factors and personal factors, these latter not classified in the ICF.

Increasingly, countries are enhancing their data about functioning and disability using the ICF. The ICF is an international standard for health and disability information - key for collecting valid, reliable and comparable health and disability data. To be a standard for harmonization and comparability, however, the ICF has to be applied consistently around the world by all users. Therefore, the aims and rationale of the ICF, and the specific skills needed to use it, must be taught in an accessible and standardized manner (Raggi et al. 2010; Tempest et al. 2012, 2013).

The ICF comprises 1424 categories from the components: body functions, body structures, activities and participation and environmental factors, which are organized in a hierarchical structure (Fig. 2). Categories are divided into chapters, which constitute the first level of specification. High-level categories (e.g. second, third or fourth level) are more detailed.

An ICF category is coded by the component letter and a suffix of 1 to 5 digits. The letters $\mathbf{b}, \mathbf{s}, \mathbf{d}$ and $\mathbf{e}$ refer to the components: body functions (b), body structures (s), activities and participation (d) and environmental factors (e). This letter is followed by a one-digit number indicating the chapter, the code for the second level (2 digits), and the codes for the third and fourth levels (1 digit each). The component letter with the suffixes of 1, 3, 4 or 5 digits corresponds to the code of the ICF categories. Within each component, the categories are arranged in a stem/branch/leaf scheme. This scheme indicates that a more detailed, high-level category covers all the aspects applicable for the low-level category, of which it is a member, but not vice versa. Numerous reports on the use of the ICF have been published both in theoretical and clinical context (Cerniauskaite et al. 2011; Maribo et al. 2016). There is a trend towards development of ICF-based assessment tools through identification of relevant categories. The most common ICF-derived generic assessment 


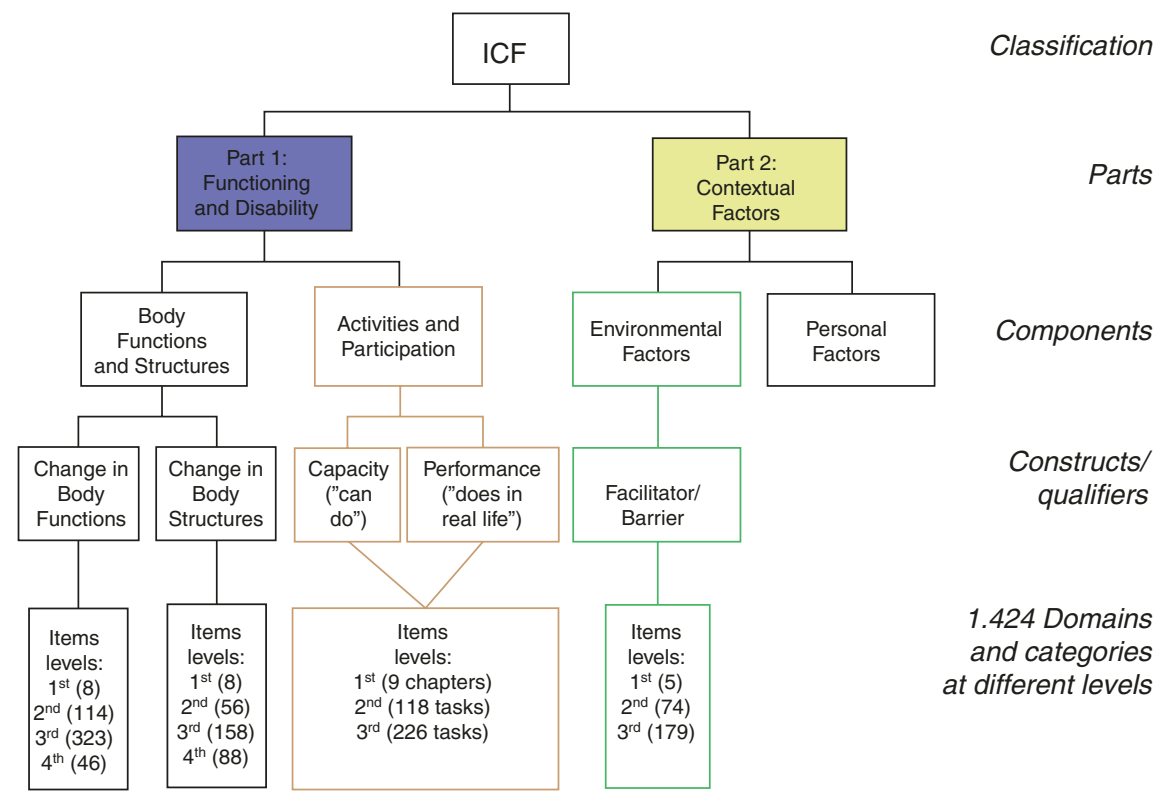

Fig. 2 Structure of the World Health Organization's International Classification of Functioning, Disability and Health (ICF)

tool is the WHO DAS 2.0 Disability Assessment Schedule (Ustun et al. 2010; Garin et al. 2010; Schlote et al. 2009). For stroke, a disease-specific core set was released in 2004 (Geyh et al. 2004).

\section{$4 \quad$ ICF-Based Common Language in Reporting and Documentation Along the Care Pathway of Stroke Patients}

Using the ICF as the common language to describe clinical findings at different time points and between different specialists makes it easy to establish a shared reporting system avoiding ambiguities and inconsistencies arising from sectoral reports (i.e. 'transferring oneself' might be labelled as 'mild activity limitation' by one and 'moderate activity limitation' by another team member). Here it is noteworthy to separate description of clinical findings from description of interventions, which arise as a consequence to findings at different time points. A classification of interventions is currently under development by WHO to provide a common tool for reporting and analysing health interventions for statistical purposes. The International Classification of Health Interventions (ICHI) is built around three axes: Target (the entity on which the action is carried out), Action (a deed done by an actor to a target) and Means (the processes and methods by which the action is carried out) (WHO 2017). 
Establishing such a shared reporting system is helpful to monitor progresses from admission to discharge travelling through milestones (in terms of progress or setbacks) in a reasonable way minimizing reporting efforts. Prior to that, a common understanding on reasons for and content of reporting as well as a common understanding of the basic concepts of the framework should have been elaborated within the rehabilitation team (Raggi et al. 2010; Tempest et al. 2012, 2013). Having achieved an agreement on individual responsibilities for reporting, a shared ICFbased documentation system can be established easily, fulfilling all legal requirements for traceability.

\subsection{ICF-Based Scales and Assessments}

Standardized measurement tools support and inform clinical decision-making and communication with others (Tyson et al. 2010; Rosewilliam et al. 2011; Brown et al. 2013; Plant et al. 2016). Also, feedback on progresses to patients and relatives are much more likely to be understood if standardized assessments are used (Tyson et al. 2014b; Levack et al. 2015). To enhance comparability of health information collected in different settings, linking rules are available to serve as a basis for evidence-based decision-making across all levels of health systems (Cieza et al. 2004, 2016). The Academy for Neurologic Physiotherapy (ANPT) published a review on a total of 54 outcome measures in the ICF categories. Most of them are linked to body function (mostly musculoskeletal and sensation) and Mobility and Self-Care Activities and participation codes (ANPT 2015).

\subsection{ICF-Based Goal Setting}

In a systematic review of the ICF, Yen and colleagues found benefits for integrating the ICF into goal-setting practice. They concluded that the use of the ICF in healthcare goal-setting provides clinicians and patients with specific steps to follow when attempting to set goals collaboratively (Yen et al. 2014).

\section{Theoretical Background in Goal-Setting Practice}

\subsection{Goal-Setting Theory (Locke and Latham)}

According to goal-setting theory, three types of goals are to be distinguished: outcome goals (winning), performance goals (doing well by your own standards) and process-oriented or learning goals (learning skills for improving performance). This triad, originally developed in sports, might also be useful in rehabilitation.

- Outcome goals play an important role, where goal attainment depends on the performance of competitors. Within the context of neurorehabilitation, this type of goals has not been investigated so far but might play a role in group settings when patients compare among themselves. 
- Performance goals prompt individuals to use routines or strategies that they have previously acquired and which are effective in performing the task. Individual ability is a key factor, and key questions are: How often, how well, under which circumstances will you act?

- In contrast, process/learning/mastery goals frame the goal instructions in terms of knowledge or skill acquisition (e.g. discover effective strategies to cope with impairments). Consequently, a learning goal draws attention away from a specific end result towards discovering and acquiring appropriate strategies, processes or procedures necessary to perform a given task. The key questions are: How will you achieve it? What can you do?

Stretch goals are intentionally set at levels that are 'seemingly unattainable with present resources'. Stretch goals have been used in business units as a supplement to 'required' or 'minimally acceptable' goals. Their purpose is to stimulate creative, 'outside-the-box' thinking with the intent to generate new ideas for improving business units' performance. (Kerr and Lepelley 2013). In the context of neurorehabilitation, stretch goals may not be applicable for individual goal setting but for team development. Furthermore, if individuals self-set their goals at an unrealistic level, it might be helpful to label them as stretch goals and put in relation individuals' importance with experts' views of difficulty to achieve this stretch goal, alongside a number of sub-goals including goals related to 'perceiving and appreciating individual's task capacity/performance' and 'managing risk behaviour'. Furthermore, it will be helpful to establish a commitment on short-time sub-goals, which mediate the relationship between actual performance and self-efficacy.

Already in 1967, Locke has demonstrated a clear linear relationship between the degree of goal difficulty and performance, if set within the limit of the individual's ability. This has been confirmed in several studies since then. (Locke and Latham 2002). Goal setting was found to have a greater positive effect on tasks that were straightforward (uncomplicated and easy to do) and on tasks that people already had the knowledge and skills to perform well.

Approach-oriented goal statements ('mind obstacles') induce self-efficacy and search-for-information behaviour, whereas avoidance-oriented goal statements ('avoid falls') are associated with reduced goal adherence (Wood et al. 2013). Furthermore, a positive relationship between goal specificity, goal importance and goal commitment has been demonstrated. Therefore, wording of goals and instructions might impact on goal commitment and adherence. Here, the acronym: RUMBA (relevant, understandable, measurable, behavioural, achievable) has turned out to be an appropriate mnemonic (Braun et al. 2010).

\subsection{Goal Setting and Action Planning (Scobbie)}

Scobbie et al. (2011, 2013) developed and implemented theory-based Goal setting and Action Planning framework (G-AP, Fig. 3) suitable for in-patient and community-based stroke rehabilitation. The framework is based on three main pillars: the Goal-Setting Theory (Locke and Latham 1990, 2013a), the Social Cognitive Theory (Bandura 2010, 2013) and the Health Action Process Approach (Sniehotta et al. 2005, 2016). 

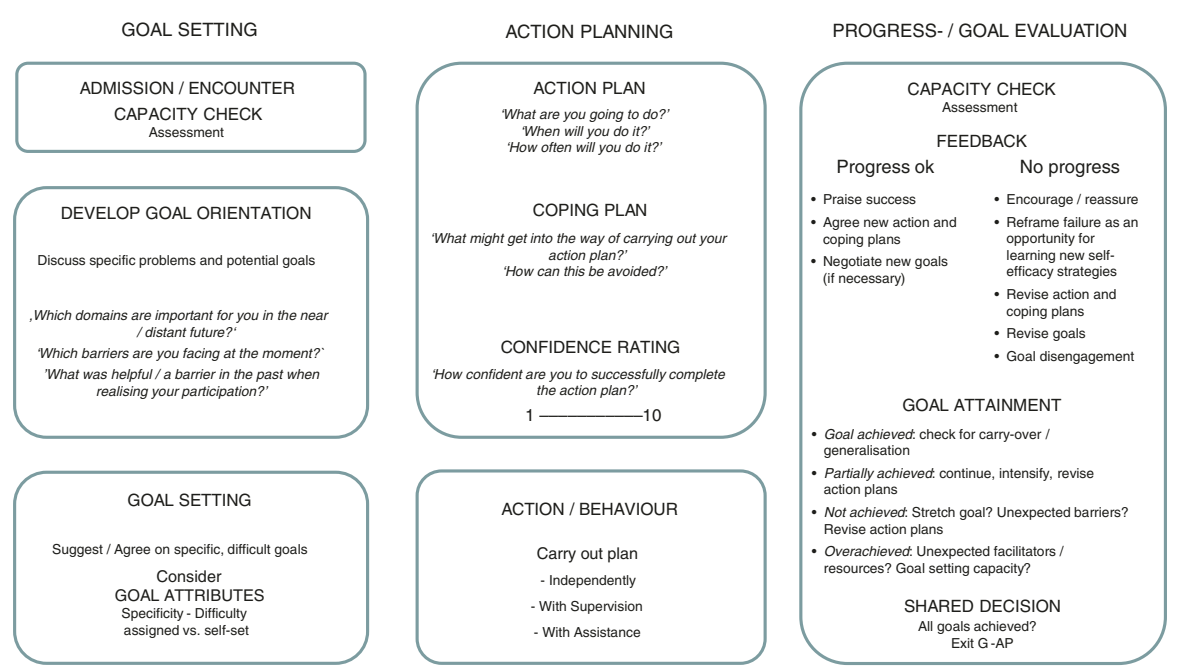

Fig. 3 Goal setting—action planning framework. (Modified from Scobbie et al. 2011)

The framework starts with a capacity check in relevant life domains (with/without assistance/devices) to identify a baseline level and develop possible goal intentions. Here, the beneficial effects of legitimate authorities/experts and a supportive leadership must not be underestimated (Locke and Latham 2013b). Nevertheless, active engagement of the stroke survivors in goal setting and treatment planning appears to be a central factor for developing self-management skills and for social participation after stroke (Woodman et al. 2014).

Having established specific, attractive, difficult and agreed goals, the next stepsetting up action plans and reviewing coping strategies with respect to individual's confidence to accomplish a task successfully-forces us to think about treatment strategies which patients are likely to follow. To optimize self-regulation, planning has proven useful (Sniehotta et al. 2005). This planning can be divided into two sub constructs serving different purposes. The first sub construct, action planning, specifies the intended action in terms of when, where, and how to act (implementing intentions to act). The second sub construct, coping planning, refers to coping strategies to prioritize the intended behaviour over the habitual responses when obstacles or barriers are faced.

Successful engagement in everyday activities is influenced by feedback from others, usually accepted persons such as family, friends and experts. Cianci and colleagues found that healthy individuals with learning goal instructions performed better after negative feedback but worse after positive feedback, whereas performance declined when negative feedback was combined with performance goals (Cianci et al. 2010).

Feedback also has affective consequences. Individuals feel joy or disappointment based in part on feedback regarding their success or failure to attain a goal. As feedback represents attention from a (usually accepted) person in the environment, a social component may also play an important role. Simply knowing that someone 
cares and is attending to the individual's progress may motivate him or her (Ashford and de Stobbeleir 2013).

\subsection{Goal Achievement and Goal Attainment Scaling}

Outcome measurement is required to determine the effectiveness of rehabilitation interventions. Goal achievement has been considered to be an important outcome measure (Hurn et al. 2006). It depends on two things: the patient's ability to achieve their goals and the clinician's ability to predict outcome, which requires knowledge and experience (Turner-Stokes 2009). Within the G-AP framework, evaluation of goal achievement (appraisal and feedback) is a distinct and important intervention aiming to enhance self-efficacy and set the basis for (guided) self-management, marking the transition from 'therapy' (receptive) to 'training' (active, self-set).

If goals are 'achieved as expected', interventions usually come to an end and patients should have gained a higher level of independence. If goals are 'partially achieved', further treatment and/or changes of action plans might be required. Goals will be 'not achieved', if individuals (self-)set their goals at an unrealistic level. Allowing difficult stretch goals alongside, 'realistic' goals during goal negotiation might be helpful to increase insight into and acceptance of limited recovery.

One way of quantifying the achievement of goals for statistical and research purposes beyond simply recording achievement as a 'pass' or 'fail' is through goal attainment scaling (Kiresuk and Sherman 1968). Goal attainment scaling (GAS) is a method of scoring the extent to which patient's individual goals are achieved in the course of intervention. When using goal attainment scaling, tasks are individually identified and set around current and expected levels of performance. In effect, each individual has its own outcome measure, but this is scored in a standardized way as to allow statistical analysis. (Turner-Stokes 2009). If goal performance at baseline is rated -1 (some activities, could worsen), an initial T-score around 35-40 (depending on the number of goals) will result. If all goals are achieved as expected (rating 0 ), a T-score of 50 will be achieved. An overachievement of goals leads to a value above, an under or partial achievement below 50 .

Concerns about GAS have been raised about non-linearity of the scaling and lack of uni-dimensionality (Tennant 2007). Multiple variations on the original GAS approach have been published such as using a different number of levels of goal achievement (from -3 to +3 ) (Turner-Stokes and Williams 2010) and a different scoring system than was originally proposed, involving greater patient participation in goal selection and having the treating therapist rather than an independent thirdparty select and re-evaluate the GAS goals (Cytrynbaum et al. 1979; Turner-Stokes 2009). Finally, there is no agreed approach to goal setting (McPherson et al. 2014; Wade 2009). Some authors have proposed the development of standardized goals or 'item banks'. (Tennant 2007). Nevertheless, there is growing evidence that goal attainment scaling is a good person-centred outcome measure for rehabilitation (Hurn et al. 2006; Ashford and Turner-Stokes 2006; Turner-Stokes et al. 2009), although GAS is not a measure of outcome per se, but a measure of achievement of 
intention. It depends on the quality of goal setting as well as on the quality of treatment. Hence, it does not replace standardized measures at the moment until validity of GAS has been demonstrated by studies investigating correlations with standardized measures. Finally, important but difficult (stretch)goals likely to be 'not achieved' will lead to lower T-scores, if counted. Therefore, no added value arises from calculating individual T-scores in clinical practice, as patients and clinicians prefer words to numbers.

\subsection{Examples on ICF-Based Goal Setting}

ICF-based goal statements usually denominate a task/an action (what?) followed by modifiers describing circumstances (how?) for successfully accomplishing the task (such as time, number repetitions and contextual factors such as aids and devices, assistance).

In early phases of stroke rehabilitation, gaining or improving functioning and establishing independence is in the center of all attempts (Wood et al. 2010). In ICF terminology, most relevant goals are about mobility (d4) and self-care (d5). After discharge home, stroke survivors are confronted with the remaining impairments of several body function impacting on their usual activities (d6 domestic life, d7 interactions and relations and $\mathrm{d} 9$ social and civic life). Usually these areas are not very likely to be covered by initial goal setting, such is not 'handling stress and other psychological demands' (d240). Especially in persons with several impairments causing severe disability, goals related to interactions and relations such as 'making/ holding eye contact — for a few minutes in quiet/lively environment' or 'signalling discomfort/agreement/dissent—spontaneously/after being asked...' are very useful to guide caregivers and the team to work towards the same goal. The classification of environmental factors allows also to define what facilitates or hinders the functioning of the patients.

Currently, only a few attempts have been made to develop standardized goals or 'item banks'. Here, the ICF offers an agreed framework for goal areas, which easily can be adopted for individual goal setting. Examples are given in Table 1.

\section{Goal Setting in Stroke Patients in Practice}

In a Cochrane review on goal setting and strategies to enhance goal pursuit in neurorehabilitation, Levack et al. (2015) found 39 studies published before December 2013, involving a total of 2846 participants receiving rehabilitation in a variety of countries and clinical situations. They identified at least 12 different approaches to goal setting with a lot of variations regarding goal identification, selection, prioritizing, goal characteristics, the use for intervention planning, etc. Yet, they identified two common features in goal setting: having measurable goals and involving patients in goal setting. The review found an increase in health-related quality of life or self-reported emotional status (8 studies, 446 participants; standardized mean 
Table 1 ICF-based goal examples - setting up a goal agreement document

\begin{tabular}{|c|c|c|}
\hline \multirow[t]{9}{*}{ d1 } & Learning and applying knowledge & Context (how?) \\
\hline & Observing obstacles & $\begin{array}{l}\text { Spontaneous/on advice/in quiet/lively environment- } \\
\text { Despite hemianopia/neglect... }\end{array}$ \\
\hline & Observing the left side of space & $\begin{array}{l}\text { Spontaneous/on advice/in quiet/lively environment- } \\
\text { Despite hemianopia/neglect... }\end{array}$ \\
\hline & Recognising danger (at home) & $\begin{array}{l}\text { Spontaneous/after feedback/with cues/under } \\
\text { supervision ... }\end{array}$ \\
\hline & $\begin{array}{l}\text { Recognising own capabilities } \\
\text { (potential) }\end{array}$ & $\begin{array}{l}\text { With regard to ... } \\
\text { Spontaneous/after feedback/with support ... }\end{array}$ \\
\hline & Focussing attention up to $\ldots$ mins & In in quiet/lively environment/with distractors... \\
\hline & Solving (simple/complex) problems & Spontaneous/with advice/feedback/assistance ... \\
\hline & Taking decisions regarding ... & Spontaneous/with advice/feedback/assistance ... \\
\hline & $\ldots$ & \\
\hline \multirow[t]{9}{*}{ d2 } & General tasks and demands & Context (how?) \\
\hline & $\begin{array}{l}\text { Using means of orientation, memory, } \\
\ldots\end{array}$ & Spontaneous/with advice/cues/assistance ... \\
\hline & $\begin{array}{l}\text { Using swallowing strategies (chin } \\
\text { down...) }\end{array}$ & Spontaneous/with advice/cues/assistance ... \\
\hline & $\begin{array}{l}\text { Performing stretching/strengthening } \\
\text { exercises }\end{array}$ & Spontaneous/with advice/cues/assistance ... \\
\hline & Planning and conducting daily routine & $\begin{array}{l}\text { Independently/with assistance/considering own level } \\
\text { of resources... }\end{array}$ \\
\hline & $\begin{array}{l}\text { Taking breaks before overtiredness, } \\
\text { pain attacks }\end{array}$ & Spontaneous/with advice/cues/assistance ... \\
\hline & $\begin{array}{l}\text { Using pain control strategies } \\
\text { (breathing, muscle relaxation, ...) }\end{array}$ & Spontaneous/with advice/cues/assistance ... \\
\hline & $\begin{array}{l}\text { Fixing wheelchair brakes before } \\
\text { standing up }\end{array}$ & Spontaneous/with advice/cues/assistance ... \\
\hline & $\ldots$ & \\
\hline \multirow[t]{7}{*}{ d3 } & Communication & Context (how?) \\
\hline & Understanding short/long messages & $\begin{array}{l}\text { After first hearing/after one repetition/in quiet/lively } \\
\text { environment ... }\end{array}$ \\
\hline & $\begin{array}{l}\text { Starting/sustaining/ending a } \\
\text { conversation with one person/several } \\
\text { persons }\end{array}$ & $\begin{array}{l}\text { Spontaneously, about familiar/current topics; with/ } \\
\text { without help from communication partner ... }\end{array}$ \\
\hline & $\begin{array}{l}\text { Participating in a conversation with } \\
\text { (more than) one person(s) }\end{array}$ & $\begin{array}{l}\text { With - w/o help from a familiar partner/despite word } \\
\text { finding difficulties }\end{array}$ \\
\hline & $\begin{array}{l}\text { Communicating ones needs and } \\
\text { wishes }\end{array}$ & Verbally/with gestures/by signing/writing ... \\
\hline & $\begin{array}{l}\text { Using communication devices (e.g. } \\
\text { phone, text, emails ...) }\end{array}$ & $\begin{array}{l}\text { Independently/with the help of a familiar person in a } \\
\text { protected environment }\end{array}$ \\
\hline & $\ldots$ & \\
\hline
\end{tabular}


Table 1 (continued)

\begin{tabular}{|c|c|c|}
\hline \multirow[t]{9}{*}{ d4 } & Mobility & Context (how?) \\
\hline & $\begin{array}{l}\text { Getting out of bed; standing up; } \\
\text { sitting down... }\end{array}$ & $\begin{array}{l}\text { Independently/with a rail/supervised/guided/with help } \\
\text { of (un-)skilled person... }\end{array}$ \\
\hline & Sitting, standing, squatting, kneeling & $\begin{array}{l}\text { For \# mins., independently/holding on a rail/ } \\
\text { supervised/with help of (un-)skilled person... } \\
\text { With additional activity, in quiet/lively environment }\end{array}$ \\
\hline & Getting up from the floor & $\begin{array}{l}\text { Spontaneously, without help, with layperson's/ } \\
\text { professional help, ... }\end{array}$ \\
\hline & $\begin{array}{l}\text { Walking in house/out of the house/for } \\
\text { short - Long distance }\end{array}$ & $\begin{array}{l}\text { Independently/with an orthosis/cane/wheeled walker } \\
\text { Supervised/with help of (un-)skilled person... } \\
\text { On slopes, on grass/snow/gravel ... }\end{array}$ \\
\hline & $\begin{array}{l}\text { Grasping, lifting and carrying objects } \\
\text { such as a pencil/a coin/a glass/... }\end{array}$ & $\begin{array}{l}\text { With one hand/both hands; up to ... kg, while sitting/ } \\
\text { standing ... }\end{array}$ \\
\hline & Opening water bottles & $\begin{array}{l}\text { With both hands, despite reduced strength, with } \\
\text { eye-hand-control ... }\end{array}$ \\
\hline & $\begin{array}{l}\text { Manipulating small objects such as } \\
\text { coins, needles, buttons, ... }\end{array}$ & With both hands, spontaneously, after instruction .... \\
\hline & $\ldots$ & \\
\hline \multirow[t]{9}{*}{ d5 } & Self-care & Context (how?) \\
\hline & Washing face/arm/chest/legs/oneself & $\begin{array}{l}\text { Independently/prepared utensils/final control/ } \\
\text { supervised/guided/with help of (un-) skilled person, in } \\
\text { adequate time/in customized/unexperienced } \\
\text { environment... }\end{array}$ \\
\hline & Dressing oneself & $\begin{array}{l}\text { Independently/prepared clothes/final control/ } \\
\text { supervised/guided/with help of (un-) skilled person, in } \\
\text { adequate time/in customized/unexperienced } \\
\text { environment... }\end{array}$ \\
\hline & Showering/bathing & Independently, prepared utensils ... \\
\hline & $\begin{array}{l}\text { Brushing one's teeth, combing, } \\
\text { shaving ... }\end{array}$ & Independently, prepared utensils ... \\
\hline & $\begin{array}{l}\text { Eating/drinking (food/drink } \\
\text { consistency to be defined according } \\
\text { level of functioning) }\end{array}$ & $\begin{array}{l}\text { Independently/supervised/with help of (un-)skilled } \\
\text { person; with -w/o swallowing strategy, adapted cutlery, } \\
\text { drinking straw; ... }\end{array}$ \\
\hline & Taking care for the paretic arm & $\begin{array}{l}\text { Independently/with reminder/supervised/guided } \\
\text { In customized /unexperienced environment... }\end{array}$ \\
\hline & Taking one's medicine & Independently/with reminder/supervision/help... \\
\hline & $\ldots$ & \\
\hline \multirow[t]{8}{*}{ d6 } & Domestic life & Context (how?) \\
\hline & Shopping & $\begin{array}{l}\text { With a shopping list, by using an 'aphasia id', } \\
\text { independently/supervised/with the help of ..., }\end{array}$ \\
\hline & Preparing simple/complex meals & $\begin{array}{l}\text { Independently/supervised/with the help of ..., } \\
\text { By using aids such as ..., in adequate time .... }\end{array}$ \\
\hline & $\begin{array}{l}\text { Cleaning the kitchen/the bath/... } \\
\text { Using a vacuum cleaner ... }\end{array}$ & $\begin{array}{l}\text { Independently/supervised/with the help of ..., } \\
\text { By using aids such as ..., in adequate time .... }\end{array}$ \\
\hline & $\begin{array}{l}\text { Washing/drying one's clothes/ } \\
\text { hanging up clothes/ironing }\end{array}$ & Independently/with reminder/supervision/help... \\
\hline & $\begin{array}{l}\text { Carrying out garden work (using a } \\
\text { shovel/rake/shears ...) }\end{array}$ & $\begin{array}{l}\text { For ... mins./taking pauses after .... mins., } \\
\text { Independently/with reminder/supervision/help... }\end{array}$ \\
\hline & $\begin{array}{l}\text { Looking after the (grand-)children, } \\
\text { animals... }\end{array}$ & For $\ldots$ hours, $\ldots$ \\
\hline & $\ldots$ & \\
\hline
\end{tabular}


Table 1 (continued)

\begin{tabular}{|c|c|c|}
\hline \multirow[t]{9}{*}{ d7 } & $\begin{array}{l}\text { Interpersonal interactions and } \\
\text { relationships }\end{array}$ & Context (how?) \\
\hline & $\begin{array}{l}\text { Making eye contact/holding eye } \\
\text { contact }\end{array}$ & $\begin{array}{l}\text { For ... mins., in quiet/lively environment, after having } \\
\text { been told ... }\end{array}$ \\
\hline & $\begin{array}{l}\text { Signalling discomfort/agreement/ } \\
\text { dissent... }\end{array}$ & Spontaneously/after having been asked, ... \\
\hline & $\begin{array}{l}\text { Showing respect/warmth/appreciation } \\
\text { (to familiar/unknown persons, in a } \\
\text { group of peers, ...) }\end{array}$ & $\begin{array}{l}\text { Spontaneously, with cues, on advice, with (un-) } \\
\text { structured feedback, with help... }\end{array}$ \\
\hline & $\begin{array}{l}\text { Maintaining social distance (gender } \\
\text { related, in a group of peers, towards } \\
\text { staff members...) }\end{array}$ & $\begin{array}{l}\text { Spontaneously, with cues, on advice, with (un-) } \\
\text { structured feedback, with help... }\end{array}$ \\
\hline & $\begin{array}{l}\text { Accepting help (for walking/eating/ } \\
\text { toileting ...) }\end{array}$ & $\begin{array}{l}\text { Spontaneously, with cues, on advice, with (un-) } \\
\text { structured feedback, ... }\end{array}$ \\
\hline & $\begin{array}{l}\text { Sticking to agreements/rules } \\
\text { (regarding walking/eating/toileting } \\
\text {..) }\end{array}$ & $\begin{array}{l}\text { Spontaneously, with cues, on advice, with (un-) } \\
\text { structured feedback, ... }\end{array}$ \\
\hline & $\begin{array}{l}\text { Getting in touch/maintain contact } \\
\text { with peers (Parkinson, Aphasia, MS } \\
\text {...) }\end{array}$ & After preparation, with an escort, ... \\
\hline & $\ldots$ & \\
\hline \multirow[t]{7}{*}{ d8 } & Major life areas & Context (how?) \\
\hline & Working on a computer & $\begin{array}{l}\text { Independently, for ... mins., with adapted keyboard, in } \\
\text { quiet/noisy environment ... }\end{array}$ \\
\hline & Conducting voluntary work & $\begin{array}{l}\text { For up to \# hrs/week, with guidance/supervision/help } \\
\text { of ... }\end{array}$ \\
\hline & $\begin{array}{l}\text { Taking part in a professional } \\
\text { retraining course }\end{array}$ & Independently/with help, ... \\
\hline & Paying one's bills & Independently/with the help of ..., \\
\hline & Conducting one's bank affairs & Independently/with the help of ..., \\
\hline & $\ldots$ & \\
\hline \multirow[t]{7}{*}{ d9 } & Community, social and civic life & Context (how?) \\
\hline & Participating in family/social life & $\begin{array}{l}\text { Spontaneously/with help, for ... hrs/day, with familiar } \\
\text { people/strangers, ... }\end{array}$ \\
\hline & Visiting friends & $\ldots$ \\
\hline & Playing cards/chess/boards games ... & Independently, with familiar people, $\ldots$ \\
\hline & $\begin{array}{l}\text { Going swimming/horse riding/ } \\
\text { climbing/cycling ... }\end{array}$ & Independently/with help, regularly, ... \\
\hline & Voting in elections & Independently ... \\
\hline & $\ldots$ & \\
\hline
\end{tabular}

First column: to denominate goal agreement status (agreed with patient/relatives/significant others) Second column: to denominate the task/action (what task?)

Third column: to denominate the context/circumstances (how will it work?)

Fourth column: level of goal attainment at date of follow-up (achieved—partially—not achieved— overachieved) (not included here) 
difference (SMD) $0.53,95 \%$ confidence interval (CI) 0.17 to 0.88 ; quality of evidence very low) and self-efficacy (3 studies, 108 participants; SMD 1.07, 95\% CI 0.64 to 1.49 ; quality of evidence very low) when some form of goal setting (plus or minus strategies to enhance goal pursuit) was used in comparison to no goal setting. No consistent evidence was found that goal setting impacts on impairments. There was insufficient information whether goal setting increases or reduces the risk of adverse events or justifies additional costs for goal setting and action planning. Because of the variety of approaches to studying goal setting in rehabilitation and because of limitations in the design of many studies completed to date, the authors expect that 'it is very possible that future studies could change the conclusions of this review' (Levack et al. 2015).

Two reviews of goal setting within the context of stroke rehabilitation concluded that active patient participation in goal setting appeared to be something that patients value and that structured methods of goal setting seem to increase patients' perceptions of their level of involvement in clinical decision-making (i.e. enhancing a sense of self-determination); however, the effects of a patient-centred goal-setting practice in stroke rehabilitation have been studied mostly with weak methodologies (Rosewilliam et al. 2011; Sugavanam et al. 2013).

Plant and colleagues reviewed barriers and facilitators to goal setting during stroke rehabilitation. Nine qualitative papers were selected, involving 202 participants in total: 88 patients, 89 healthcare professionals and 25 relatives of participating patients (Plant et al. 2016). The main barriers to goal setting during stroke rehabilitation were: a mismatch between patients' and staff's perspective; lack of confidence by the staff to manage patient expectations; patients' stroke-related impairments and lack of time and ineffective organizational systems. The main facilitators were: early, frequent, active communication with patient and family; individually tailoring the goal-setting process; effective, confident and encouraging staff; education of patients and families; providing support and educational materials and adequate resources. They concluded that current methods of goal setting during stroke rehabilitation are not fit for purpose.

\section{Recommendations for Multidisciplinary Team Approach and ICF-Based Goal Setting in Stroke Rehabilitation}

If possible, stroke rehabilitation should be delivered by interdisciplinary teams with specific training and experience in the field (level of evidence 1a, quality of evidence moderate, $\mathrm{B}+$ ).

The early rehabilitation process after stroke should be initiated in a stroke units (level of evidence 1a, quality of evidence moderate, $\mathrm{B}+$ ).

Since the rehabilitation process after stroke will rarely be complete when it is time to leave hospital, rehabilitation should be continued after discharge especially during the first year after stroke to reduce the risk of disability and may individually be needed at later stages (level of evidence 5, quality of evidence very low, B+ [clinical relevance]0). 
For delivering high-quality healthcare for stroke survivors, the integration (in contrast with fragmentation) of care providers (e.g. specialists, general practitioners and other healthcare providers such as pharmacists, nurses, psychologists, physiotherapists) and close coordination (multidisciplinary care) of their activities across levels of care and multiple sites is warranted, all of which can be optimally embedded within a system that promotes patient empowerment (level of evidence 5, quality of evidence very low, 0 ).

Heightened attention should be spent to evaluate team processes related to assessing/reporting of clinical findings and to goal setting and action planning processes. This includes to review the structure of team meetings, encourage the use of standardized measurement tools and assessments for clinical status and progress monitoring and the explicit method used for goal setting and action planning. (Level of evidence $2 \mathrm{~b}$, quality of evidence low, $\mathrm{B}+$ [clinical relevance]).

All domains, including the body functions and structures (impairment), the activity and participation as well as the environmental factors domain of the ICF, can be used as a common language for professionals when setting goals in a semistructured, 'guided' manner. Using the main ICF activity and participation domain as broad goal categories will prevent from missing important goal areas, such as, interactions and relations and social and civic life. (Level of evidence 5, quality of evidence very low, 0 ).

Heightened attention can be spent to the goal syntax (starting with a verb, denominating a task, followed by modifiers, denominating the circumstances to accomplish the task). Patient's perceptions/appraisal of goal importance, goal difficulty, self-efficacy and emotional stability can be checked, as they will mainly impact on individual goal choice and ranking and how to avoid goal conflicts. Evaluation of goal achievement (appraisal and feedback) can be used as a distinct and important intervention aiming to enhance self-efficacy and set the basis for (guided) self-management, marking the transition from 'therapy' (receptive) to 'training' (active, self-set). (Level of evidence 5, quality of evidence very low, 0 ).

\section{Summary}

Here, we highlight the importance of developing a common understanding of the basic concepts for reporting clinical findings at different time points and in the different setting of the care pathways as well as for goal setting using the ICF and its biopsychosocial model as an agreed language and framework.

Overcoming fragmentation by a person-centred approach in line with the Multimorbidity Chronic Care Model supports a fact-based identification of individual goals to be pursued and reached in each specific phase of the care and rehabilitation process. Goal setting and action planning processes are described alongside the underlying theoretical assumptions.

Goal setting has become a central component of effective rehabilitation practice, both as a part of the communication and decision-making process and as a 
person-centred outcome measure for stroke rehabilitation. The evidence regarding the individual contribution of specific components of the goal setting process (e.g. levels of patient involvement, levels of goal difficulty) remains inconclusive. Therefore, agreed standards on goal setting and evaluation are still lacking and current methods of goal setting in stroke rehabilitation are still quite arbitrary. This chapter provides the rationale for a more organized process along all the care pathway of stroke patients, from acute event to social reintegration and inclusion, having an ICF-based methodology that will allow the definition of all the steps.

Translating the evidence from the huge research body on goal-setting theory into clinical practice will lead to a higher impact and a more structured approach in utilizing the power of individual goal setting and action planning in the future.

\section{References}

ANPT (2015) ANPT outcome measures recommendations (EDGE) [online]. Academy of Neurologic Physical Therapy, Alexandria, VA. http://www.neuropt.org/professional-resources/. Accessed 14 Jan 2019

Ashford SJ, de Stobbeleir KEM (2013) Feedback, goal setting, and task performance revisited. In: Locke EA, Latham GP (eds) New developments in goal setting and task performance, 1st edn. Routledge, New York, London

Ashford S, Turner-Stokes L (2006) Goal attainment for spasticity management using botulinum toxin. Physiother Res Int 11:24-34

Ayerbe L, Ayis S, Wolfe CD, Rudd AG (2013) Natural history, predictors and outcomes of depression after stroke: systematic review and meta-analysis. Br J Psychiatry. 202(1):14-21. https://doi.org/10.1192/bjp.bp.111.107664.

Bandura A (2010) Self-efficacy: the exercise of control. Freeman, New York

Bandura A (2013) The role of self-efficacy in goal-based motivation. In: Locke EA, Latham GP (eds) New developments in goal setting and task performance, 1st edn. Routledge, New York, London

Brands IM, Wade DT, Stapert SZ, Van Heugten CM (2012) The adaptation process following acute onset disability: an interactive two-dimensional approach applied to acquired brain injury. Clin Rehabil 26:840-852

Brands I, Stapert S, Kohler S, Wade D, Van Heugten C (2014) Life goal attainment in the adaptation process after acquired brain injury: the influence of self-efficacy and of flexibility and tenacity in goal pursuit. Clin Rehabil 29:611-622

Braun JP, Mende H, Bause H, Bloos F, Geldner G, Kastrup M, Kuhlen R, Markewitz A, Martin J, Quintel M, Steinmeier-Bauer K, Waydhas C, Spies C, NEQUI (2010) Quality indicators in intensive care medicine: why? Use or burden for the intensivist. Ger Med Sci 8:Doc22

Brown M, Levack W, McPherson KM, Dean SG, Reed K, Weatherall M, Taylor WJ (2013) Survival, momentum, and things that make me "me": patients' perceptions of goal setting after stroke. Disabil Rehabil 36:1020-1026

Cerniauskaite M, Quintas R, Boldt C, Raggi A, Cieza A, Bickenbach JE, Leonardi M (2011) Systematic literature review on ICF from 2001 to 2009: its use, implementation and operationalisation. Disabil Rehabil 33:281-309

Cianci AM, Schaubroeck JM, Mcgill GA (2010) Achievement goals, feedback, and task performance. Hum Perform 23:131-154

Cieza A, Ewert T, Ustun TB, Chatterji S, Kostanjsek N, Stucki G (2004) Development of ICF core sets for patients with chronic conditions. J Rehabil Med:9-11 
Cieza A, Fayed N, Bickenbach J, Prodinger B (2016) Refinements of the ICF linking rules to strengthen their potential for establishing comparability of health information. Disabil Rehabil:1-10

Cytrynbaum S, Ginath Y, Birdwell J, Brandt L (1979) Goal attainment scaling:a critical review. Eval Q 3:5-40

Epping-Jordan JE, Pruitt SD, Bengoa R, Wagner EH (2004) Improving the quality of health care for chronic conditions. Qual Saf Health Care 13:299-305

Garin O, Ayuso-Mateos J, Almansa J, Nieto M, Chatterji S, Vilagut G, Alonso J, Cieza A, Svetskova O, Burger H, Racca V, Francescutti C, Vieta E, Kostanjsek N, Raggi A, Leonardi M, Ferrer M, CONSORTIUM, M (2010) Validation of the "World Health Organization disability assessment schedule, WHODAS-2" in patients with chronic diseases. Health Qual Life Outcomes 8:51

Geyh S, Cieza A, Schouten J, Dickson H, Frommelt P, Omar Z, Kostanjsek N, Ring H, Stucki G (2004) ICF core sets for stroke. J Rehabil Med:135-141

Hurn J, Kneebone I, Cropley M (2006) Goal setting as an outcome measure: a systematic review. Clin Rehabil 20:756-772

Kerr S, Lepelley D (2013) Stretch goals: risks, possibilities, and best practices. In: Locke EA, Latham GP (eds) New developments in goal setting and task performance, 1st edn. Routledge, New York, London

Kiresuk TJ, Sherman RE (1968) Goal attainment scaling: a general method for evaluating comprehensive community mental health programs. Community Ment Health J 4:443-453

Levack WM, Weatherall M, Hay-Smith EJ, Dean SG, McPherson K, Siegert RJ (2015) Goal setting and strategies to enhance goal pursuit for adults with acquired disability participating in rehabilitation. Cochrane Database Syst Rev 7:CD009727

Locke EA, Latham GP (1990) A theory of goal setting \& task performance. Prentice Hall, Englewood Cliffs, NJ

Locke EA, Latham GP (2002) Building a practically useful theory of goal setting and task motivation. A 35-year odyssey. Am Psychol 57:705-717

Locke EA, Latham GP (2013a) Goal setting theory: the current state. In: Locke EA, Latham GP (eds) New developments in goal setting and task performance, 1st edn. Routledge, New York, London

Locke EA, Latham GP (2013b) New developments in goal setting and task performance. London, Routledge, New York

Maribo T, Petersen KS, Handberg C, Melchiorsen H, Momsen AM, Nielsen CV, Leonardi M, Labriola M (2016) Systematic literature review on ICF from 2001 to 2013 in the Nordic countries focusing on clinical and rehabilitation context. J Clin Med Res 8:1-9

McPherson K, Kayes N, Kersten P (2014) MEANING as a smarter approach to goals in rehabilitation. In: Siegert RJ, Levack WMM (eds) Rehabilitation goal setting: theory, practice and evidence. Taylor \& Francis Group, London

Oxford Centre for Evidence-Based Medicine (2009). Levels of Evidence (March 2009). Centre for Evidence-Based Medicine. https://www.cebm.ox.ac.uk/resources/levels-of-evidence/oxfordcentre-for-evidence-based-medicine-levels-of-evidence-march-2009. Accessed 20.09.2020.

Palmer K, Marengoni A, Forjaz MJ, Jureviciene E, Laatikainen T, Mammarella F, Muth C, Navickas R, Prados-Torres A, Rijken M, Rothe U, Souchet L, Valderas J, Vontetsianos T, Zaletel J, Onder G, Joint Action on Chronic, D. \& Promoting Healthy Ageing Across the life, C (2018) Multimorbidity care model: recommendations from the consensus meeting of the joint action on chronic diseases and Promoting healthy ageing across the life cycle (JA-CHRODIS). Health Policy 122:4-11

Plant SE, Tyson SF, Kirk S, Parsons J (2016) What are the barriers and facilitators to goal-setting during rehabilitation for stroke and other acquired brain injuries? A systematic review and meta-synthesis. Clin Rehabil 30:921-930

Platz T (2017). Practice guidelines in neurorehabilitation. Neurology International Open. 1(3): E148-E152. https://doi.org/110.1055/s-0043-103057

Raggi A, Leonardi M, Cabello M, Bickenbach JE (2010) Application of ICF in clinical settings across Europe. Disabil Rehabil 32(Suppl 1):S17-S22 
Rosewilliam S, Roskell CA, Pandyan AD (2011) A systematic review and synthesis of the quantitative and qualitative evidence behind patient-centred goal setting in stroke rehabilitation. Clin Rehabil 25:501-514

Schlote A, Richter M, Wunderlich MT, Poppendick U, Möller C, Schwelm K, Wallesch CW (2009) WHODAS II with people after stroke and their relatives. Disabil Rehabil 31:855-864

Schünemann H, Brożek J, Guyatt G, Oxman A, editors (2013) GRADE handbook for grading quality of evidence and strength of recommendations. Updated October 2013. The GRADE Working Group. Available from www.guidelinedevelopment.org/handbook

Scobbie L, Dixon D, Wyke S (2011) Goal setting and action planning in the rehabilitation setting: developed and implemented a theory-based Goal setting and Action Planning framework. Clin Rehabil 25:468-482

Scobbie L et al (2013) Implementing a framework for goal setting in community based stroke rehabilitation: a process evaluation. BMC Health Serv Res 13(1):190

Sniehotta FF, Schwarzer R, Scholz U, Schüz B (2005) Action planning and coping planning for long-term lifestyle change: theory and assessment. Eur J Soc Psychol 35:565-576

Sniehotta FF, Presseau J, Allan J, Araujo-Soares V (2016) “you Can't always get what you want": a novel research paradigm to explore the relationship between multiple intentions and behaviours. Appl Psychol Health Well Being 8(2):258-275

Strasser DC, Falconer JA, Herrin JS, Bowen SE, Stevens AB, Uomoto J (2005) Team functioning and patient outcomes in stroke rehabilitation. Arch Phys Med Rehabil 86:403-409

Strasser DC, Falconer JA, Stevens AB, Uomoto JM, Herrin J, Bowen SE, Burridge AB (2008) Team training and stroke rehabilitation outcomes: a cluster randomized trial. Arch Phys Med Rehabil 89:10-15

Stroke Unit Trialists C (2013) Organised inpatient (stroke unit) care for stroke. Cochrane Database Syst Rev 2013(9):CD000197

Sugavanam T, Mead G, Bulley C, Donaghy M, Van Wijck F (2013) The effects and experiences of goal setting in stroke rehabilitation-a systematic review. Disabil Rehabil 35:177-190

Teasell R, Hussein N (2016) Background concepts in stroke rehabilitation. In: Teasell R, Foley $\mathrm{N}$, Hussein N, Speechley M (eds) Evidence-based review of stroke rehabilitation, 17th edn. London, Ontario, Canada, Sockit Solutions

Teasell R, Foley N, Hussein N, Cotoi A (2016a) The efficacy of stroke rehabilitation. In: Teasell R, Richardson M, Allen L, Hussein N (eds) Evidence-based review of stroke rehabilitation, 17th edn. London, Sockit Solutions

Teasell R, Foley N, Hussein N, Speechley M (2016b) The elements of stroke rehabilitation. In: Teasell R, Foley N, Hussein N, Speechley M (eds) Evidence-based review of stroke rehabilitation, 17th edn. London, Ontario, Canada, Sockit Solutions

Tempest S, Harries P, Kilbride C, De Souza L (2012) To adopt is to adapt: the process of implementing the ICF with an acute stroke multidisciplinary team in England. Disabil Rehabil 34:1686-1694

Tempest S, Harries P, Kilbride C, De Souza L (2013) Enhanced clarity and holism: the outcome of implementing the ICF with an acute stroke multidisciplinary team in England. Disabil Rehabil 35:1921-1925

Tennant A (2007) Goal attainment scaling: current methodological challenges. Disabil Rehabil 29:1583-1588

Turner-Stokes L (2009) Goal attainment scaling (GAS) in rehabilitation: a practical guide. Clin Rehabil 23:362-370

Turner-Stokes L, Williams H (2010) Goal attainment scaling: a direct comparison of alternative rating methods. Clin Rehabil 24:66-73

Turner-Stokes L, Williams H, Johnson J (2009) Goal attainment scaling: does it provide added value as a person-centred measure for evaluation of outcome in neurorehabilitation following acquired brain injury? J Rehabil Med 41:528-535

Tyson S, Greenhalgh J, Long AF, Flynn R (2010) The use of measurement tools in clinical practice: an observational study of neurorehabilitation. Clin Rehabil 24:74-81 
Tyson SF, Burton L, McGovern A (2014a) Multi-disciplinary team meetings in stroke rehabilitation: an observation study and conceptual framework. Clin Rehabil 28:1237-1247

Tyson SF, Burton LJ, McGovern A, Sharifi S (2014b) Service users' views of the assessment process in stroke rehabilitation. Clin Rehabil 28:824-831

Tyson SF, Burton L, McGovern A (2015) The effect of a structured model for stroke rehabilitation multi-disciplinary team meetings on functional recovery and productivity: a phase I/II proof of concept study. Clin Rehabil 29:920-925

UN (2007) Convention on the rights of persons with disabilities and optional protocol. United Nations, New York

Ustun TB, Chatterji S, Kostanjsek N, Rehm J, Kennedy C, Epping-Jordan J, Saxena S, Von Korff M, Pull C, Project, W. N. J (2010) Developing the World Health Organization disability assessment schedule 2.0. Bull World Health Organ 88:815-823

Wade DT (2009) Goal setting in rehabilitation: an overview of what, why and how. Clin Rehabil 23:291-295

Wagner EH (1998) Chronic disease management: what will it take to improve care for chronic illness? Eff Clin Pract 1:2-4

Wagle J, Farner L, Flekkøy K, Wyller T, Sandvik L, Fure B, et al (2011). Early post-stroke cognition in stroke rehabilitation patients predicts functional outcome at 13 months. Dementia and geriatric cognitive disorders 31;379-387. https://doi.org/10.1159/000328970

WHO (2001) International classification of functioning, disability and health: ICF. World Health Organization, Geneva

WHO (2017) International Classification of Health Interventions (ICHI) - Beta [online]. World Health Organisation (WHO), Geneva. http://www.who.int/classifications/ichi/en/. Accessed 11 Dec 2018

WHO \& UNESCO (2010) Community-based rehabilitation: CBR guidelines. World Health Organization, Geneva

Wood JP, Connelly DM, Maly MR (2010) 'Getting back to real living': a qualitative study of the process of community reintegration after stroke. Clin Rehabil 24:1045-1056

Wood RE, Whelan J, Sojo V, Wong M (2013) Goals, goal orientations, strategies, and performance. In: Locke EA, Latham GP (eds) New developments in goal setting and task performance, 1st edn. Routledge, New York, London

Woodman P, Riazi A, Pereira C, Jones F (2014) Social participation post stroke: a metaethnographic review of the experiences and views of community-dwelling stroke survivors. Disabil Rehabil 36:2031-2043

Yen T-H, Liou T-H, Chang K-H, Wu N-N, Chou L-C, Chen H-C (2014) Systematic review of ICF core set from 2001 to 2012. Disabil Rehabil 36:177-184

Open Access This chapter is licensed under the terms of the Creative Commons AttributionNonCommercial-NoDerivatives 4.0 International License (http://creativecommons.org/ licenses/by-nc-nd/4.0/), which permits any noncommercial use, sharing, distribution and reproduction in any medium or format, as long as you give appropriate credit to the original author(s) and the source, provide a link to the Creative Commons license and indicate if you modified the licensed material. You do not have permission under this license to share adapted material derived from this chapter or parts of it.

The images or other third party material in this chapter are included in the chapter's Creative Commons license, unless indicated otherwise in a credit line to the material. If material is not included in the chapter's Creative Commons license and your intended use is not permitted by statutory regulation or exceeds the permitted use, you will need to obtain permission directly from the copyright holder. 